\title{
Cultural characterstics of Cercospora beticola sacc. causing leaf spot of palak
}

\section{POORNIMA*AND YASHODA R. HEGDE}

Department of Plant Pathology, College of Agricultural Sciences, University of Agricultural Sciences, DHARWAD (KARNATAKA) INDIA

\begin{tabular}{|c|c|}
\hline ARITCL & INFO \\
\hline Received & : 22.07.2014 \\
\hline Revised & : 01.09 .2014 \\
\hline Accepted & : 13.09 .2014 \\
\hline
\end{tabular}

\section{KEY WORDS :}

Cercospora beticola, Cultural characters, Palak

\begin{abstract}
Palak (Beta vulagaris var. bengalensis Hort.) is one of the most popular leafy vegetables widely grown in India. This crop is severely affected by leaf spot disease caused by Cercospora beticola leading to brown coloured spots on the leaves which hinders the market quality of the leaves. All media are not equally good for all fungi, nor there is a universal substrate or artificial medium, upon which all fungi can grow. So, different media including both synthetic and non-synthetic were tried for $C$. beticola in the present experiment. Cultural studies of $C$. beticola grown on different solid media showed that Potato dextrose agar and Oat meal agar were good for growth. Among the nine liquid media evaluated, maximum dry mycelial weight of the fungus was obtained in Soypeptone broth which was significantly superior to all other media. Temperature requirement of the fungus was found $25^{\circ} \mathrm{C}$ where good growth was observed.
\end{abstract}

How to view point the article : Poornima and Hegde, Yashoda R. (2014). Cultural characteristics of Cercospora beticola sacc. causing leaf spot of palak. J. Plant Protec., 7(2) : 441-443. 